\title{
Audio-visual media to improve sexual-reproduction health knowledge among adolescent
}

\author{
Sitti Nur Djannah ${ }^{1}$, Sulistyawati Sulistyawati ${ }^{2}$, Tri Wahyuni Sukesi ${ }^{3}$, \\ Surahma Asti Mulasari ${ }^{4}$, Fatwa Tentama ${ }^{5}$ \\ ${ }^{1,2,3,4}$ Faculty of Public Health, Universitas Ahmad Dahlan, Indonesia \\ ${ }^{5}$ Faculty of Psychology, Universitas Ahmad Dahlan, Indonesia
}

\begin{tabular}{l} 
Article Info \\
\hline Article history: \\
Received Dec 1, 2019 \\
Revised Jan 15, 2020 \\
Accepted Feb 17, 2020 \\
\hline
\end{tabular}

Keywords:

Adolescent education

Audio-visual media

Knowledge

Sexual-reproduction health

\begin{abstract}
Lacking knowledge among adolescents affects their understanding of some problems related to sexual-reproduction health. Electronic media recognized as the favored source of information for adolescents. This research aimed to assess the effect of audio-visual media to the increasing of sexualreproduction knowledge. We conducted a before and after without control informal experimental study design into 153 students in the 1st-3rd grade of junior high school. The effect of the intervention was assessed through the difference between pre- and post-intervention by using the Wilcoxon test. The mean score of the respondent pre and post-intervention was significantly increasing. The audiovisual increased the knowledge of the adolescent regarding sexual-reproduction health
\end{abstract}

This is an open access article under the CC BY-SA license.

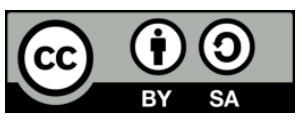

\section{Corresponding Author:}

Sulistyawati Sulistyawati, Faculty of Public Health, Universitas Ahmad Dahlan, Prof Dr. Soepomo Street, Umbulharjo, Yogyakarta, Indonesia.

Email: sulistyawatisuyanto@gmail.com

\section{INTRODUCTION}

Labors to maintain adolescent health are needed to prevent various health problems that potentially influence their quality of life, including maintaining healthy reproduction. Since the early-stage, the adolescent should be prepared to become a healthy and productive adolescent. The healthy adolescent is the national capital in the future for conducting development in a particular country because they are such investment for an adult now, adult future lives and the next generation [1]. However, a low middle-income country still suffers from a child marriage problem [2], Indonesia is one of this country. Undeniable that early-age marriage is a serious problem [3]. Some cities in Indonesia recognized exposed to this problem, namely Jakarta, Surabaya, Bandung and Yogyakarta [4].

Yogyakarta is one of the big cities with a high incidence of premarital sex. In 2015, the Yogyakarta Provincial Health Office reported that 1.078 adolescent births at school age, of which 976 were pregnant out of marriage status $[5,6]$. This situation is distressing since the previous study said that most medical problems in adolescents related to sexual behavior, particularly getting pregnant before 20 [7]. This behavior put at risk to maternal and infant deaths 2-4 timed higher compared to the pregnant woman in 20-35 of age [8]. In addition, premarital sex in adolescents could cause some sexually transmitted diseases, such as gonorrhea, syphilis, HIV / AIDS and other venereal diseases [9, 10]. Another impact on un-safe sex puts an adolescent at risk of unintended pregnancies, which may contribute to other problems such as drop out of school, marrying early, leaving babies and gaining abortions [11-13]. 
According to the Indonesia Ministry of Health report, reported that the incidence of HIV / AIDS in adolescents (15-24 years) continues to increase every year [14]. People with HIV/AIDS in Indonesia recorded 103.759 people, 13.527 among them are HIV positive aged between 20-24 years old [15]. Refer to this report, attention to adolescent behavior needs to be improved, such as by conducting health promotion. There are differences of opinion about the best approach to promote health. However, refer to the Indonesian Demographic and Health Survey [16], adolescents prefer to see electronic media as the primary source of information to increase their understanding of HIV / AIDS, fertility, pregnancy, the influence of drugs and alcohol. This evidence strengthens by another research said that sexual health information was delivered through some sources like media, religious groups, family, school, etc. [17]. Accordingly, providing sexualreproduction information to the adolescent using validate media is essential. This research aimed to assess the effect of audio-visual media to the increasing of sexual-reproduction knowledge in Junior High School students.

\section{RESEARCH METHOD}

\subsection{Setting and research design}

This study was conducted in a stated school: $4^{\text {th }}$ Junior High School of Ngoro-oro, Patuk, Gunungkidul, Yogyakarta in August 2019. This school located in a rural setting. We used total sampling on recruiting the participant. The student in 1-3 $3^{\text {rd }}$ grades was invited to join in this study. Students who did not attend the school or left early were excluded. We conducted a before and after without control informal experimental study design, such as had performed in a recent study [18]. This design allows the researcher to observe the changing of knowledge before and after the intervention as formulated in Figure 1.

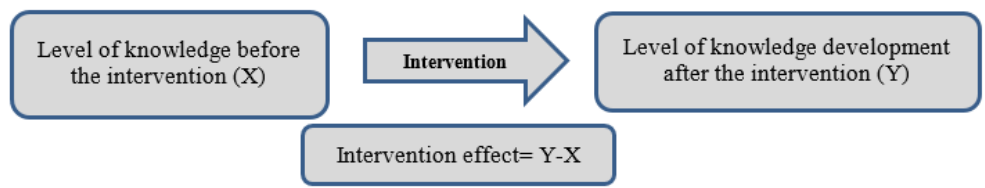

Figure 1. Study design illustration

\subsection{Intervention}

The intervention was delivered by the first author using a validation video education that received interval validation from the content expert, media expert and user. Accordingly, it is approved valid and relevant for adolescent. This video contains sexual health education on the adolescent with a duration of about 20 minutes. The various interactions were performed during intervention for keeping focus the respondent, such as by delivering simple questions to respondents.

\subsection{Pre- and post-assessments}

To assess the impact of the intervention to the respondent, a baseline assessment was carried out through pre-testing questionnaire. At the end of the intervention, the same survey was given to the respondent. The questionnaire delivered in Bahasa Indonesia consists of 41 true-false questions about adolescent health reproduction knowledge. An oral explanation was given to the respondent before the intervention was held together with the inform consent acquisition.

\subsection{Statistical analysis}

The answer to each question in the questionnaire was administrated in SPSS version 24.0 (IBM Corp., Armonk, NY, USA). The coding for every response was scored as follows: the correct answer was scored as +1 , and the wrong answer was scored as 0 . The individual total score is 41 , and the lowest score is 0 . We assessed the mean score before and after the intervention then continued with Wilcoxon test due to the data not in the normal distribution.

\subsection{Ethical considerations}

There was no harm arising from participating in this study. Respondents voluntary to participate in this study, and they are free to quit from the study anytime without consequential. Inform consent was obtained before the research started. Research data were saved by the research group with confidential and close the access without our permissions. 


\section{RESULT AND DISCUSSION}

\subsection{Respondent characteristic}

In total, 153 out of 185 students participated in this study (response rate: 82\%). Majority of respondent were female $(54 \%)$. The mean age of the respondents was 13.53 years old, majority of the respondents were of 13-14 years, as shown in Table 1.

Table 1. Sociodemographic characteristic of respondent

\begin{tabular}{ll}
\hline Variables & $\mathrm{n}(\%)$ \\
\hline Gender & \\
Males & $74(46.25)$ \\
Females & $86(53.75)$ \\
Age (years) & \\
$11-12$ & $26(16.25)$ \\
$13-14$ & $105(65.63)$ \\
$15-16$ & $29(18.12)$ \\
\hline
\end{tabular}

\subsection{Pre and post-assessments}

A comparison between pre- and post-intervention shows that our baseline means score before the intervention was 34.40, then after the intervention was 35.83 (Figure 1). Our intervention by using audiovisual successfully increased the student knowledge; it is seen from the mean of total score between pre and post-test assessment (Figure 2). The knowledge differences between the two arms were significantly increased, as shown in Table 2.

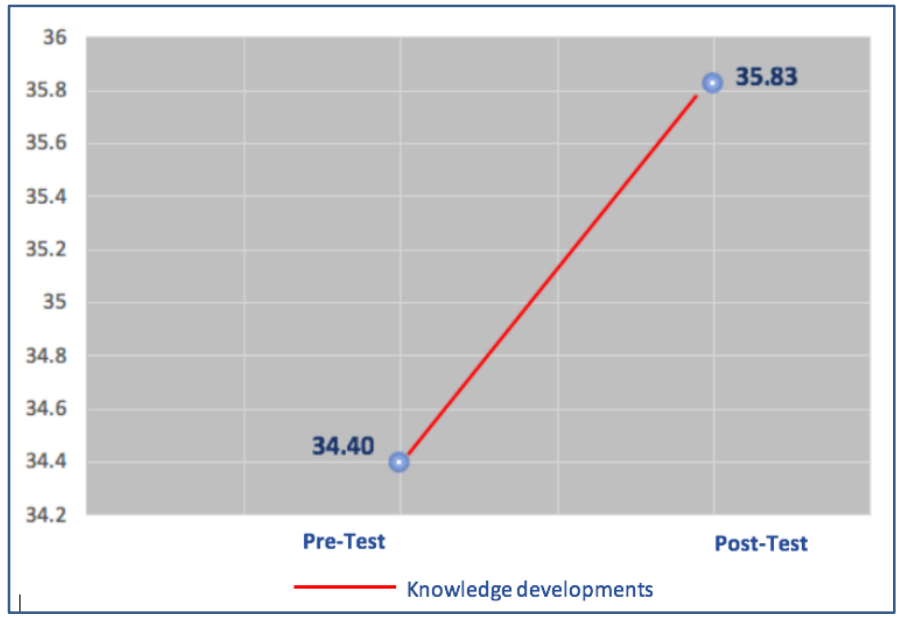

Figure 2. Pre-post assessment using mean score

Table 2. Wilcoxon test for pre and post-intervention

\begin{tabular}{cc}
\hline Variable & P-value \\
\hline Pre-Test vs Post-Test & 0.000 \\
\hline
\end{tabular}

The maximum total score for each question was 153 points. Figure 2 shows the comparison of pre and post-test responses for each question. We highlighted three questions that received less than 80 of the total score, either pre or post or both. Those questions are number 6) about everyone has different reproductive ability, 19) estrogen and progesterone are hormones in female, which also found in male, 21) reproductive hormones do not affect the physical and psychological development of girls and boy's adolescent (Figure 3). A complete questionnaire can be accessed at the supplementary. 


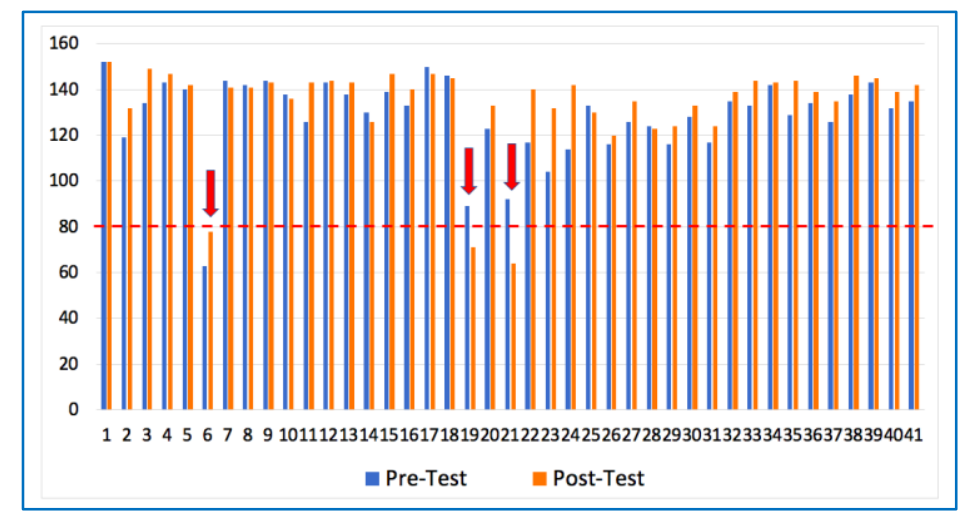

Figure 3. Total score pre and post-test for each question

Recently, sexual and reproduction health knowledge for the adolescent is essential to prepare the adolescent to face the globalization and social media era that trigger everyone to see and learn any topic without limits. The adolescent has to educate in the early stage to protect their body and future from the improper social intercourse such as turn to the free sexual behavior, child marriage, sexual out of marriage, and sexual without protection that put them at risk to dangerous disease like HIV/AIDS. Improper knowledge about reproductive health among adolescents was not only found in Indonesia, a study in Riyadh reported that more than $60 \%$ of adolescents had inaccurate knowledge [19]. Audiovisual media, both online and offline, was proved as an effective media to deliver information to adolescents [20, 21]. The main goal of this study was to increase adolescent knowledge regarding sexual and health reproduction by using audio-visual media. Our intervention provided a deep understanding of the sexual and reproductive health both for woman and man. This education encourages adolescent to recognize their part of the body and the valued their self, particularly their sexual and reproductive organ. This content is part of our concern that in Indonesia discuss reproductive health is a taboo topic [22].

This research evidently the role of audio-visual media on improving adolescent knowledge related to sexual education. This statement had proven by expert previously, who said that audio-visual media contributed to the information aspect and persuaded on positive behavioral changes [23-25]. This argument based on the reason that audio-visual media involves some senses to the participant, such as hearing, listening and visual that connects the received information to the human brain between 75 to $87 \%$ [26]. This evidence supported by another study, for instance, Edgar Dale Pyramid experiences who said that 50\% of students learn from what they see and listen [4]. Some previous research discussed the benefit of audio-visual media, such as Khatarina, $\mathrm{T}$ and Yuliana who prove that there was an association between health reproduction education through audio-visual and health reproduction knowledge [27] Correspondingly, Notoatmodjo revealed similar evidence that eye and ear are the most tools functioning to gain a good understanding [28]. From this fact, we conclude that our audio-visual can be used as media education to increase knowledge of adolescents about reproductive health.

The low response was found in some questions, which is low than 80 out of 153 . First, it was about understanding reproductive ability among human-this questions delivered to recognize respondent knowledge about the differences in reproductive ability among women and men. Even though the knowledge increased between pre and post, however, the increase was still under the 80 out of 153. This result shows that participant has a low understanding of reproductive system differences among human (woman and man). Indeed, the question was slightly vague; however, during the course of data collection, some respondents asked clarification about this question, to get more understanding. This implies that the respondents understood the meaning of the question.

This study likewise revealed the participant's knowledge about the reproductive hormone was not consistent. It can be seen from pre and post result that shows, after teaching the response declined. A similar result is seen on the question about the impact of the reproductive hormone on the physical and psychological development of girls and boy's adolescents. This unexpected result implies that respondent understanding about the reproductive hormone is low. Another possibility was related to an uncomfortable place on the intervention course since the venue was had tight space that might influence the questionnaire fulfillment. Besides, the understanding of adolescents on reproductive hormones on their body is essential for their future since it can be beneficial to maintain their fertility [29]. Understanding of puberty stage for youth is useful for undergoing the various change during their life [30]. 
This research may have a limitation, which was conducted in an insufficient situation. The number of respondents is a large amount, on another side, the venue is quite small. Accordingly, participants jostle each other, which may influence the information acceptance, likewise the convenience of questionnaire fulfillments. From this research, we suggest to the related stakeholder to act on the reproductive health among the adolescent. It can be done by inserting the topic on formal education or do the informal counseling with strengthening to the particular topic. In addition, audio-visual media can be used to support this purpose.

\section{CONCLUSION}

From this research can be concluded that audio-visual media have a significant role in increasing the sexual-reproduction health knowledge among adolescent. It is found that adolescent knowledge was insufficient related human reproductive hormone and human reproductive system. Future research suggested studying developing media for teaching-related human hormone and reproductive systems.

\section{ACKNOWLEDGMENTS}

We would like to thank SMP $4^{\text {th }}$ of Patuk, Gunungkidul and all participants who help us during the research course. This research was funded by the Ministry of Research and Technology of Indonesia with grant number L1/001/C.6/III/2019.

\section{REFERENCES}

[1] WHO, Global Accelerated Action for the Health of Adolescents (AA-HA!) Guidance to Support Country Implementation, Geneva, 2017.

[2] Q. Wodon et al., "Economic impacts of child marriage: global synthesis report," in Economic Impacts of Child Marriage: Global Synthesis Report, vol. 7, no. 1, 2017.

[3] S. Monica, "The effectiveness of school-based sex education programs in the promotion of abstinent behavior: A meta-analysis," Health Educ. Res., vol. 17, no. 4, pp. 471-481, 2002.

[4] D. N. Sari, A. Darmana, and I. Muhammad, "The effect of predisposition factors, allowers, and supporters to sexual behavior of adolescent at Asuhan Daya Senior High School Medan," J. Kesehat. Glob., vol. 1, no. 2, pp. 53-60, 2018.

[5] Kresna, "Within a year, 976 Yogyakarta students became pregnant out of wedlock (in Bahasa)," Merdeka.com, 2016. [Online]. Available: https://www.merdeka.com/peristiwa/dalam-setahun-976-pelajar-yogyakarta-hamil-diluar-nikah.html. [Accessed: 01-Dec-2019].

[6] The World Bank, Accelerating Uganda's Development: Ending Child Marriage, Educating Girls, 2017.

[7] A. R. Mellanby, F. A. Phelps, N. J. Crichton, and J. H. Tripp, "School sex education: An experimental programme with educational and medical benefit," Br. Med. J., vol. 311, no. 7002, pp. 414, 1995.

[8] N. P. Sari, "Comparative study of audio visual and peer group counseling on adolescent reproductive health knowledge levels at SMP N 1 Ngaglik Sleman Yogyakarta," Universitas 'Aisyiyah Yogyakarta (UNISA), 2015.

[9] M. S. Ghebremichael and M. D. Finkelman, "The effect of premarital sex on sexually transmitted infections (STIs) and high risk behaviors in women," Lancet, vol. 5, no. 2, pp. 59-54, 2013.

[10] N. T. Subbarao and A. Akhilesh, "Knowledge and attitude about sexually transmitted infections other than HIV among college students," Indian J. Sex. Transm. Dis. AIDS, vol. 38, no. 1, pp. 10, 2017.

[11] Y. Mi, et al., "Promoting sexual responsibility among young people in Zimbabwe," vol. 27, no. 1, pp. 11-19, 2019.

[12] G. Tuyisenge, C. Hategeka, and R. A. Aguilera, "Should condoms be available in secondary schools? Discourse and policy dilemma for safeguarding adolescent reproductive and sexual health in Rwanda," Pan Afr. Med. J., vol. 31, pp. 1-12, 2018

[13] WHO, "Adolescent pregnancy," Web, 2018. [Online]. Available: https://www.who.int/news-room/factsheets/detail/adolescent-pregnancy. [Accessed: 15-Jan-2020].

[14] Ministry of Health of Republic Indonesia, General situation of HIV/AIDS and HIV test, Jakarta, 2018.

[15] Ministry of Health of Republic Indonesia, Data and Information Center of the Ministry of Health of the Republic of Indonesia. Jakarta, 2015.

[16] National Family Planning Coordinating Agency, Indonesia Health and Demographic Survey, Jakarta, 2017.

[17] C. C. Breuner and G. Mattson, "Sexuality education for children and adolescents," Pediatrics, vol. 138, no. $2,2016$.

[18] S. Sahranavard, A. Esmaeili, H. Salehiniya, and B. Susan, "The effectiveness of group training of cognitive behavioral the1. Silva JAC da, Souza LEA de, Ganassoli C. Qualidade de vida na terceira idade: prevalência de fatores intervenientes TT - Quality of life in the elderly: prevalence of intervening factors. R," J. Educ. Health Promot., vol. 8, pp. 1-11, 2019.

[19] S. M. Gaferi, M. F. Al-Harbi, S. M. Yakout, and A. T. Soliman, "Knowledge, attitude and practice related to reproductive health among female adolescents," J. Nurs. Educ. Pract., vol. 8, no. 8, pp. 53, 2018.

[20] S. Akram and S. K. Malik, "Use of audio visual aids for effective teaching of biology at secondary schools level level," Leadersh. Manag., vol. 50, pp. 10597-10605, 2012. 
[21] V. Strasburger, B. Wilson, and A. Jordan, Children, Adolescents, and the Media, 2nd ed. Thousand Oaks, CA: SAGE, 2009.

[22] R. Gazadinda, "Reproductive health for indonesian youth (in Bahasa)," Kompasiana, Jakarta, 2019.

[23] C. Dermawan, A and Setiawati, "Learning Process in Health Education (in Bahasa), Jakarta: Trans Info Media, 2008.

[24] M. A. Wakefield, B. Loken, and R. C. Hornik, "Use of mass media campaigns to change health behaviour," Lancet (London, England), vol. 376, no. 9748, pp. 1261-71, 2010.

[25] B. J. Saunders and C. Goddard, "The role of mass media in facilitating community education and child," Child Abus. Prev. Issues, no. 16, pp. 1-24, 2002.

[26] I. Machfoedz and E. Suryani, Health Education Part of Health Promotion (in Bahasa). Yogyakarta: Fitramaya, 2009.

[27] T. Khatarina, "151/5000 Effects of reproductive health counseling through audio visuals with knowledge results after counseling in Youths of SMA Negeri 2 Pontianak in 2017," J. Kebidanan, vol. 7(1), pp. 47-54, 2017.

[28] Notoadmojo, Health Promotion and Health Behavior (in Bahasa). Jakarta: Rienika Cipta, 2011.

[29] J. L. Cameron, "Hormonal mediation of physiological and behavioral processes that influence fertility," in The national academies panel for the workshop on the biodemography of fertility and family behavior committee on population, Washington DC: National Academies Press (US), 2000.

[30] American psychological association, A reference for professionals: Developing Adoloscents, Washington DC, 2002 